\title{
Cardio-respiratory symptoms in panic disorder: a contribution from cognitive-behaviour therapy
}

\author{
Sintomas cardiorrespiratórios no transtorno de pânico: uma \\ contribuição da terapia cognitivo-comportamental \\ Anna Lucia Spear King ${ }^{1}$, Adriana Cardoso de Oliveira e Silva², Alexandre Martins Valencça ${ }^{3}$, Antonio Egidio Nardi ${ }^{4}$
}

\section{Keywords}

Panic, anxiety, phobia, exposures.

\section{Palavras-chave}

Pânico, ansiedade, fobia, exposições.

\begin{abstract}
Objective: To compare patients with panic disorder with agoraphobia treated with cognitive-behavioural therapy (CBT) associated with the medication with patients treated only with medication and verify the behaviour of the cardio-respiratory symptoms of both groups. Methods: Randomized sample in the Psychiatry Institute of the Federal University of Rio de Janeiro, divided in two groups of 25 participants each. Group 1 undertook 10 weekly sessions of CBT with one hour of duration each together with medication. Group 2, Control, were administered medication that only consisted of tricyclic anti-depressants and selective inhibitors of the re-uptake of serotonin. Evaluation instruments were applied at the beginning and to the end of the interventions. Results: According to the applied scales, group 1 showed statistically more significant results than group 2, with: reduction of panic attacks, cardio-respiratory symptoms, anticipatory anxiety, agoraphobia avoidance and fear of bodily sensations. Conclusion: Exposures (in vivo and interoceptive), especially for induction symptom exercises and relaxation, were considered essential to prepare patients with panic disorder to handle future cardio-respiratory symptoms and panic attacks with agoraphobia.
\end{abstract}

\section{RESUMO}

Objetivo: Comparar pacientes com transtorno de pânico com agorafobia, tratados com terapia cognitivo-comportamental (TCC) e medicação, com pacientes com o mesmo diagnóstico, tratados apenas com medicação, e verificar o comportamento dos sintomas cardiorrespiratórios em ambos os grupos. Métodos: Amostra randomizada com 50 voluntários diagnosticados no Instituto de Psiquiatria da Universidade Federal do Rio de Janeiro, dividida em dois grupos de 25 pacientes: o grupo 1 realizou 10 sessões semanais e individuais de TCC com uma hora de duração combinada com medicação. O grupo 2, controle, foi tratado apenas com medicação. A medicação para ambos os grupos consistiu de antidepressivos tricíclicos e inibidores seletivos de recaptação da serotonina. Instrumentos de avaliação foram aplicados no início e ao final das intervenções. Resultados: De acordo com as escalas aplicadas, o grupo 1 apresentou resultados estatisticamente mais significativos do que o grupo 2, com redução dos ataques de pânico, dos sintomas cardiorrespiratórios, ansiedade antecipatória, esquiva agorafobia e medo das sensações corporais. Conclusão: As exposições (in vivo e interoceptivas) e os exercícios de indução dos sintomas e de relaxamento foram considerados essenciais para os pacientes aprenderem a lidar com o transtorno de pânico, com os ataques e com as possíveis situações agorafóbicas futuras.

1 Federal University of Rio de Janeiro (UFRJ), Psychiatry Institute (IPUB), Panic and Respiration Laboratory (LABPR), National Institute of Technological Science - Translational Medicine (INCT - Translational Medicine/CNPq), Rio de Janeiro, Brazil.

2 Federal University Fluminense (UFF), Laboratory of Thanatology and Psychometrics, LABPR/IPUB/UFRJ - INCT-TM.

3 UFF, Medical Sciences Centre, LABPR/IPUB/UFRJ - INCT-TM/CNPq.

4 LABPR/IPUB/UFRJ - INCT-TM/CNPq.

Address for correspondence: Anna Lucia Spear King

Rua Almirante Gomes Pereira, 8 (casa), Urca - 22291-170 - Rio de Janeiro, RJ, Brasil

Tel.: (55 21) 2295-4477/(55 21) 9219-1233

E-mail: annaluciaking@gmail.com 


\section{INTRODUCTION}

Panic disorder $(\mathrm{PD})^{1}$ is characterized by the presence of frequent and recurrent acute attacks of anxiety, followed by physical and cognitive symptoms originating from mistaken associations of body sensations (BS) related to a premonition of something serious or of some potential illness. According to the cognitive theory ${ }^{2}$, due to this cognitive distortion, the individual assumes a badly adapted level of behaviour and loses the capability of identifying BS as natural forms of reactions stemming from the physiological mechanisms of adaptation ${ }^{3}$.

We hypothesized that patients with panic disorder may reduce their number of panic attacks after the cognitive behavioural therapy (CBT) ${ }^{4}$ sessions with symptom induction exercises (SIE) $)^{5}$ and can also learn to deal with the cardiorespiratory symptoms such as tachycardia and abnormal breathing.

Individuals with PD fear BS, and frequently suffer from panic attacks ${ }^{6}$ (PAs) in certain stressful situations. PAs are described as traumatic, aggressive, and unpredictable.

$\mathrm{CBT}^{4}$ has the characteristic of being a short and well recommended type of psychotherapy for the treatment of PD. Its methods include psycho education (educational techniques for the individual to learn to deal with anxiety and ample knowledge by the patient of the disorder in question), respiratory re-education (RR) exercises; progressive muscular relaxation (PMR) and cognitive restructuring (CR), which consists of giving a new meaning to the mistaken thought levels, are procedures of great importance in CBT. Finally, Interceptive exposure (IE) techniques have the objective of correcting catastrophic interpretations of the physical symptoms (bodily sensations) experienced by the patient. In vivo exposure (IVE) of the individual to feared places or situations is considered to be the primary intervention applied in the treatment, so that the patient with PD can overcome agoraphobic avoidance?.

During the patient's treatment, the techniques of $\mathrm{IE}$ and IVE are intended to interact to assist in the remission of the components of cognitive dysfunctions that are linked to agoraphobic avoidance and to autonomic symptoms verified in PD. According to Rangé ${ }^{8}, C B T$ is very efficient when compared to placebo, psychopharmacological treatments ${ }^{9,10}$, and other forms of psychotherapy. However, some studies $^{11,12}$ have shown a good clinical response of panic disorder only to psychopharmacological treatment.

IE and IVE can be administered by means of SIE and personal contact of the person with places and situations that the person has specifically defined as stressful. The successful overcoming of the initial stages of the treatment by the patient is required for the success of the subsequent steps. From the application of these exposures, the patient builds new internal defences that make him or her capable of staying naturally in prolonged contact with their own BS.
The objective of this study is to compare PD patients treated with CBT associated with antipanic medication and patients treated only with antipanic medication and observe the evolution of cardio-respiratory symptoms in both groups.

\section{METHODOLOGY}

\section{Patient selection}

For inclusion in the research the criteria adopted was, patients over 18 years old of both sexes with a diagnosis of PD with agoraphobia and no serious comorbidities. Patients that showed alcohol or drug dependency, mental retard, or serious mental disorders were excluded from the study. The randomized controlled trials were undertaken at the Panic and Respiration Laboratory (LABPR) at the Psychiatry Institute (IPUB) of the Federal University of Rio de Janeiro (UFRJ) and National Institute of Technologic Science - Translational Medicine (INCT-TM).

All patients who agreed to participate in the study signed a "Term of Free and Clarified Consent" and were made aware of all the procedures to be undertaken, as approved by the Committee of Ethics for the research IPUB/UFRJ.

Patients with PD with agoraphobia were diagnosed by clinical psychiatrists from the team at the LABPR/IPUB/UFRJ, according to the diagnostic criteria of the Manual of Diagnostic and Statistics of Mental Disorder ${ }^{1}$ and the Structured Clinical Interview Diagnostic (SCID-I) evaluation instrument ${ }^{13}$.

The sample consisted of 50 voluntary patients divided into two groups by means of a random draw. The first group ( $n=25$ ) received 10 sessions of CBT in conjunction with pharmacotherapy. The second group, the control group (n $=25$ ), received only medication. The patients started on concomitant medication and CBT.

We found that there was no loss in the sample. Fifty two volunteers were evaluated in the total survey. Of all the study volunteers, only two dropped out. We noted that all the remaining volunteers felt welcome and receptive to the study from the beginning and therefore continued till the end.

Of the two who dropped out, one was due to travel and the other just dropped without any explanation. The raters were blind to refer patients to one group or another.

Variables before and after treatment were collected by the same psychologist evaluator with training in cognitive behavioural therapy, the same professional also implemented all the scales and questionnaires. This professional psychologist received supervision from a multidisciplinary team from the LABPR/IPUB/UFRJ.

\section{Patient evaluation}

With a view to comparing the results of the groups after the interventions, the following evaluation instruments were ap- 
plied at the beginning and at the end of the research: Beck Anxiety Inventory ${ }^{14}$; Sheehan Disability Scale ${ }^{15}$; Global Assessment of Functioning (AXIS V) ${ }^{13}$; questionnaire of fears and phobias $^{16}$; questionnaire of cognitive agoraphobias ${ }^{17}$; questionnaire of body sensations ${ }^{17}$; and Panic and Agoraphobia Scale ${ }^{18}$.

The scales used in the study sought to assess anxiety, fears, phobias, bodily sensations, and the individual's ability to work, to relate socially and with his or her family, among others. The scales were selected in order to answer the questions inherent in the study. Assessments were made only at the beginning and at the end of the study, there being no application of scales during treatment.

\section{Pharmacotherapy}

Tricyclic anti-depressants (TAD) or selective serotonin reuptake inhibitors (SSRI) were prescribed with fortnightly reevaluation and/or sending to CBT treatment. The SSRI used in this study was paroxetine $20 \mathrm{mg}$ once daily and $150 \mathrm{mg}$ of TAD imipramine was also administered once daily.

Patients were not receiving medication before the study and began to use it from the beginning of the study. The psychiatrist after the collection of personal records and the data obtained in SCID was able to make a diagnosis from clinical signs and prescribe the medication best suited, TAD or SSRI.

\section{Cognitive-behavioural therapy}

The 10 CBT sessions were based on an earlier study ${ }^{19}$ with some modifications and adaptations appropriate to the characteristics of patient population being studied. The contents of the sessions were distributed in the following way: psycho education, agoraphobia, panic, and hyperventilation; respiratory re-education (RR) exercises; progressive muscular relaxation (PMR) ${ }^{20}$ exercises; preparation of a scale of patient fears, ordered from the smallest to the greatest cause of anxiety; identification of cognitive distortions; cognitive restructuring (CR); symptom induction exercises (SIE); IE; IVE; reinforcement of conquests; observation of procedural difficulties; and maintenance of treatment gains.

Patients were encouraged to apply cognitive strategies at home (for example, to expose themselves to changes of temperature, physical exercise, and other sources of anxiety) several times, with the purpose of inducing and tolerating the sensations without therapeutic assistance. Learning in the first treatment phase of the treatment that body sensations related to panic are not really dangerous is essential to overcoming agoraphobia and controlling panic.

\section{Standard model of the 10 CBT sessions}

First session: Psycho education concerning the trajectory of PD and relaxation techniques. RR exercise: Placing ones hand above ones stomach, feeling the air passing through the diaphragm, with perception of the abdominal move- ment at each respiration. Slow inspiration through the nose while counting to three, holding the respiration while counting to three, and releasing the air slowly through the mouth while counting to six. Repetition of the exercise several times in a row. PMR is undertaken with the individual, whereby the individual respectively tenses and relaxes each of four muscle groups (face; arms, shoulders, chest, and neck; abdomen, spine, and genitals; legs and feet) for ten seconds each of tensioning and relaxing.

\section{Second S}

Session: Explanation concerning the physiological mechanism of "fight and flight" between the sensation originating from this mechanism and BS that emerge from panic. Conducting the RR exercise. The patient should understand that when one manages to alter thoughts referring to the capacity to deal with feared situations, one is capable of controlling physical symptoms.

Third session: Modelling of hyperventilation, as delineated by the exaggerated rhythm and depth of respiration in the context of the needs of the body at a given moment. Hyperventilation modelling ${ }^{5}$ as the patient inspires and expires deeply for 90 seconds, observation of patient reactions and explanation of the reason for the emerging symptoms. Conducting the RR exercise. The patient should understand that anticipated anxiety is characterized by anticipatory thought processes (generally negative) of feared situations.

Fourth session: SIE: sitting, the patient looks fixedly at a light for one minute and afterwards stands up quickly and tries to read something. Analysis with the patient of the sensations felt and the levels of negative, catastrophic, and repetitive thoughts that have occurred. The patient begins to understand the origin of their symptoms and to perceive them as inoffensive. Conducting the RR exercise.

Fifth session: Explanation of the concepts of BS that can be accentuated due to a situation or to substances. Examples include: exercising oneself or moving oneself quickly, brusque changes of temperature, bright light, and use of caffeine, alcohol, medicines, and irregular levels of respiration. Conducting SIE: turning around in circles for one minute, and understanding and giving a new positive significance to the reactions verified after stopping. Conducting the RR exercise immediately after IE.

Sixth session: Patient complaints during PAs included: "I cannot breathe", "I am going to suffocate", "I am going to lose control", "I am going to die", "I am going to have a heart attack" or I am going mad". The concepts of hyperventilation are remembered and SIE from the $4^{\text {th }}$ session is repeated, followed by the RR exercise.

Seventh session: Education concerning CR. The patient should try to identify and give a new significance to specific badly-adapted thoughts. The concepts of anticipated an- 
xiety (AA) and agoraphobic avoidance (PA-aa) ${ }^{7}$ are clarified. Patients have the custom of myths in relation to PA, including but not limited to: the patient is instructed to question and contest his or her conjectures and beliefs, concentrate on realistic probabilities, and gather evidence and formulas to deal with events.

Eighth session: The IE refers to the fear learned from internal states. Certain sensations of terror, similar to previously experienced fear, may precipitate new $\mathrm{Pas}^{6}$. The automatic stimulus generated intensifies the feared sensations, creating a vicious circle. Conduct two SIEs: first, the patient sits down and places their head between their legs for $30 \mathrm{sec}-$ onds, after which they sit up quickly and look to the ceiling. Second, the patient holds their breath until it can no longer be held while turning around in circles for 30 seconds. In continuity, analysis of the symptoms and trying to understand the originating causes. RR exercise is conducted.

Ninth session: Conduct three SIEs: first, repeat the SIE from the $5^{\text {th }}$ session. Then follow the first SIE with the two SIEs from the $8^{\text {th }}$ session. Subsequently conduct the RR exercise. The purpose for the patient is to associate the symptom with the cause. Explain that the symptoms emerge from physiological alterations triggered for some reason, and that BS do not emerge from nowhere, with no apparent reason. Before CBT, the patient would make distorted associations of facts, interpreting tachycardia, perspiration, and loss of breath, among others, as signs of imminent death or loss of control, and not as resulting from specific triggering factors.

Tenth session: Conduct one SIE: the patient standing up and turns his or her head from side to side for 30 seconds, stops, and tries to fix his or her eyes on a spot on the wall. Repeat this exercise after the SIE from the third session, in continuity; recover the patient's physical balance and respiration with RR or PMR exercises. Evaluate the IVE concept regarding confronting the patient with agoraphobic situations or locations. Real confrontation with the feared situation was repeated with each item on the priority list of each patient's fears, beginning with the least anxiety-provoking and culminating with the most feared. Patients were asked to practice IVE whenever possible. The IVEs conducted were reviewed, practical repetitions were encouraged, and difficulties in the procedures were discussed with each patient.

The therapist stimulated thoughts concerning the avoided tasks and helped the patients with CR. The fact was commented upon that additional diagnostics, including comorbidities such as depression, generalized anxiety and social phobia, tended to decline after PD treatment. The therapist also reaffirmed that the fear response was inoffensive, passing, and controllable, and that BS appear and disappear and do no need to be actively avoided.

After the end of all the stages of the research, the two groups were re-evaluated with the same initial instruments. The groups were compared, and the changes that had oc- curred, relative benefits, losses, and differences between the two groups were observed and documented.

\section{Statistical analysis}

Inferential analysis of the results was undertaken by means of Chi-square tests for several categories and analysis of variance (ANOVA) for the continuous variables, considering the differences between the averages of the scores obtained by the participants at the beginning and the end of treatment, in each of the separate evaluator instruments. In the characterization of the groups, the tests were undertaken with the values identified at the beginning of treatment. Thus, the efficiency of the initiatives undertaken could be perceived.

The confidence interval was arbitrated at 95\% and p-values $\leq 0.05$ were considered significant. Data processing and analysis were conducted using SPSS software (version 14.0).

\section{RESULTS}

\section{Patient characteristic}

Table 1 presents the socio-demographic and clinical features of the general population and clinical comorbidity (both groups).

Administered pharmacotherapy: in the intervention group $44 \%$ of patients were using TAD and $56 \%$ used SSRI, while in the control group we observed $64 \%$ of patients with TAD and $36 \%$ with SSRI.

\section{Age of the participants}

Group 1 and group 2 (control) differed significantly in age. The minimum age for both groups was 22 and the maximum was over 55 years old. However, the average age for the group 1 was 44.5 (standard deviation, SD = 12.8; confidence interval $(\mathrm{Cl})(95 \%)=39.0-49.8)$ and for the Control group (2) was $33.7(\mathrm{SD}=9.6 ; \mathrm{Cl}(95 \%)=29.7-37.7)$. The analysis of variance (ANOVA) test of means showed 0.000 significance, which is lower than the $P$ - value 0.05 , with $95 \%$ confidence.

\section{Test results}

At the end of the study, cardio-respiratory symptoms, PAs, anticipated anxiety, agoraphobic avoidances and fear of BS were significantly reduced in group 1 compared to group 2 (Table 2). In the global assessment of functioning scale, group 1 increased its overall well-being from 60.8 to 72.5 , while overall well-being in group 2 progressed, but to a slightly lesser extent, $66.0 \%$ to $71.3 \%$. In the respiratory subtype ${ }^{21}$ PAs, the following respiratory symptoms were prominent during PAs: sensation of suffocation, respiratory difficulty, paresthesias, dizziness, and fear of death ${ }^{22}$. It was observed that $77.6 \%$ of the surveyed patient population presented the respiratory subtype and $22.4 \%$ presented the non-respiratory subtype. 
Table 1. Socio-demographic and clinical descriptions of the general population

\begin{tabular}{|c|c|c|}
\hline & n & $\begin{array}{c}\% \text { or } \\
\text { Mean (Standard } \\
\text { Deviation) }\end{array}$ \\
\hline Age & 50 & $\begin{array}{l}39,08( \pm 12,46) \\
\text { Minimum }=22 ; \\
\text { Maximum }=67\end{array}$ \\
\hline \multicolumn{3}{|l|}{ Sex } \\
\hline Male & 39 & $78 \%$ \\
\hline Female & 11 & $22 \%$ \\
\hline \multicolumn{3}{|l|}{ Marital status } \\
\hline Single & 18 & $36 \%$ \\
\hline Married & 21 & $42 \%$ \\
\hline Separated & 11 & $11 \%$ \\
\hline \multicolumn{3}{|l|}{ Religion } \\
\hline Roman catholic & 31 & $62 \%$ \\
\hline Evangelical & 11 & $22 \%$ \\
\hline Other & 8 & $16 \%$ \\
\hline \multicolumn{3}{|l|}{ Schooling } \\
\hline First grade & 14 & $28 \%$ \\
\hline Second grade & 19 & $38 \%$ \\
\hline Higher education & 17 & $34 \%$ \\
\hline Years of study & 50 & $\begin{array}{r}11,82( \pm 3,39) \\
\text { Minimum }=6 ; \\
\text { Maximum }=20\end{array}$ \\
\hline \multicolumn{3}{|l|}{ Occupational situation } \\
\hline Working & 27 & $54 \%$ \\
\hline Away from work/on leave from work & 10 & $20 \%$ \\
\hline Other & 13 & $26 \%$ \\
\hline \multicolumn{3}{|l|}{ Subtype of PD } \\
\hline Non-respiratory & 14 & $28 \%$ \\
\hline Respiratory & 36 & $72 \%$ \\
\hline \multicolumn{3}{|l|}{ Clinical comorbidity } \\
\hline No & 21 & $42 \%$ \\
\hline Yes & 29 & $58 \%$ \\
\hline \multicolumn{3}{|l|}{ Psychiatric comorbidity } \\
\hline No & 26 & $52 \%$ \\
\hline Yes & 24 & $48 \%$ \\
\hline
\end{tabular}

The combination of CBT with pharmacotherapy was efficacious for Group 1, compared to the control group 2. The results of these tests were classified, according to sociodemographic data, presence of patients with physical and psychic comorbidity, and administration of medication.

The test results of group 1 are summarized in table 2 . Of the tests applied, 6 (67\%) showed positive results in group 1. In the scale of panic and agoraphobia, anticipated anxiety symptoms were satisfactorily reduced from 2.9 to 2.1; PAs were reduced from 1.4 to 0.7; agoraphobic avoidance was reduced from 2.4 to 1.6. In scale of Global Assessment of Functioning (GAF)', which was scored from 0 to 100 and considered psychological, social, and occupational function in a hypothetical continuum, group 1 obtained a significant statistical increase in global well-being from 60.8 to 72.5 .
Patients in group 1 showed a reduced loss of control from 2.8 to 2.1 , and reduced fears of physical problems from 2.6 to 2.0, as evaluated by the agoraphobic cognitions questionnaire ${ }^{17}$. Patients in group 1 also showed reduction in general anxiety from 34.9 to 20.0, as evaluated by the Beck Anxiety Inventory ${ }^{14}$; and reductions in individual work disability from 5.2 to 0.4 ; in social life disability from 4.8 to 2.2 , and in family life disability from 4.6 to 1.8 , as evaluated by the Sheehan Disability Scale ${ }^{15}$. Overall, personal disability in Group 1 was reduced from 14.6 to 4.4.

Symptoms in group 1 resulting from PD (including tachycardia, breathlessness, dizziness, tingling, nausea, perspiration, and disorientation, among others), was verified through the application of the Body Sensation questionnaire ${ }^{17}$. The results showed a general reduction from 3.1 to 2.4.

PA in group 1 was reduced from 1.4 to 0.7 , in avoidance agoraphobia was reduced from 2.4 to 1.6 , and anticipated anxiety was reduced from 2.9 to 2.1 , as evaluated by the panic and agoraphobia scale ${ }^{18}$. Overall, group 1 reduced the main behaviours verified in PD from 27.9 to 18.6.

Group 2 did not show significant statistical differences between the beginning and the end of the treatment. The results of the Sheehan scale showed that the only revealing factor leading to comprehension of the difference in the Sheehan total and Sheehan work value scales is the strong independent association of the Sheehan work value scale with psychiatric comorbidity, when controlled for by the other variables.

It is worth noting that group 2 (the control group) has more individuals with psychiatric comorbidities than group 1. This may explain the distinct difference between the Sheehan total and Sheehan work results.

The psychiatric comorbidity of depression is responsible for depressive symptoms that can interfere in the professional work and social life of the individual.

The Sheehan scale showed significant variation in relation to family when the final averages of group 1 and group 2 were compared. However, this variation is no longer relevant when the results are controlled against the other variables. If there are real differences between group 1 and group 2 , they may be due simply to pharmacotherapy, with or without CBT.

The group receiving medication alone had fortnightly contact with the psychiatrist as well as with the psychologist for progress of treatment monitoring. We truly believe that this group was at a disadvantage compared to the group that received 10 sessions of CBT, borne out in final results of the study, from the benefits achieved in a number of aspects with exposure to CBT, such as reduction of panic attacks, reduction in hyperventilation and cardio-respiratory symptoms and learning about the restructuring of negative thoughts, among others. The study was relevant in demonstrating the important role of CBT in the treatment of panic disorder. 
Table 2. Comparison between the Intervention and Control groups percentage of responders at the end of treatment period

\begin{tabular}{|c|c|c|c|c|c|c|c|c|c|}
\hline \multirow{2}{*}{ Tests } & \multicolumn{2}{|c|}{ Group 1(G1) } & \multirow{2}{*}{ Sig Dif.** } & \multicolumn{2}{|c|}{ Group 2 (G2) } & \multirow{2}{*}{ Sig Dif.** } & \multirow{2}{*}{ G1 (\%) } & \multirow{2}{*}{ G2 $(\%)$} & \multirow{2}{*}{ Sig Dif.** } \\
\hline & Baseline & 1 Week & & Baseline & 1 Week & & & & \\
\hline BAI (Beck Anxiety Inventory) & $34.9 \pm 11.2$ & $20.0 \pm 7.3$ & 0.001 & $29.3 \pm 15.3$ & $26.8 \pm 12.0$ & 0.531 & 60 & 56 & 0.116 \\
\hline Sheehan Disability Scale - Total & $14.6 \pm 3.2$ & $4.4 \pm 0.8$ & $<0.001$ & $13.2 \pm 4.3$ & $10.3 \pm 4.2$ & 0.228 & 44 & 36 & 0.013 \\
\hline Sheehan Work & $5.2 \pm 1.1$ & $0.4 \pm 0.1$ & $<0.001$ & $4.0 \pm 1.6$ & $3.0 \pm 1.8$ & 0.290 & 52 & 60 & 0.001 \\
\hline Sheehan Social & $4.8 \pm 2.0$ & $2.2 \pm 0.6$ & 0.009 & $4.7 \pm 2.0$ & $3.5 \pm 2.0$ & 0.195 & 32 & 28 & 0.179 \\
\hline Sheehan Family & $4.6 \pm 1.9$ & $1.8 \pm 0.8$ & 0.005 & $4.5 \pm 1.2$ & $3.8 \pm 1.5$ & 0.451 & 48 & 44 & 0.035 \\
\hline Phobic Fear Questionnaire (PFQ) - Total & $49.4 \pm 17.2$ & $38.3 \pm 9.7$ & 0.186 & $44.6 \pm 5.8$ & $39.5 \pm 13.2$ & 0.491 & 56 & 60 & 0.872 \\
\hline PFQ - Agoraphobia Score & $20.2 \pm 3.3$ & $14.7 \pm 3.5$ & 0.132 & $14.1 \pm 2.8$ & $14.1 \pm 5.7$ & 0.990 & 64 & 68 & 0.860 \\
\hline PFQ - Blood Score & $15.6 \pm 3.8$ & $11.6 \pm 1.8$ & 0.207 & $15.6 \pm 4.8$ & $13.8 \pm 3.9$ & 0.531 & 48 & 40 & 0.431 \\
\hline PFQ - Sociability Score & $13.7 \pm 4.2$ & $12.0 \pm 2.1$ & 0.584 & $14.9 \pm 5.0$ & $11.6 \pm 5.4$ & 0.118 & 52 & 60 & 0.882 \\
\hline Agoraphobic Cognitions Questionnaire (ACQ) & $2.7 \pm 0.5$ & $2.1 \pm 0.8$ & 0.012 & $3.9 \pm 2.1$ & $2.3 \pm 1.3$ & 0.283 & 60 & 52 & 0.233 \\
\hline ACQ - Loss of Control & $2.8 \pm 1.4$ & $2.1 \pm 1.0$ & 0.021 & $2.3 \pm 1.2$ & $2.3 \pm 1.2$ & 0.852 & 68 & 76 & 0.384 \\
\hline ACQ - Physical Problems & $2.6 \pm 0.6$ & $2.0 \pm 0.6$ & 0.027 & $2.7 \pm 1.3$ & $2.4 \pm 0.9$ & 0.114 & 44 & 40 & 0.161 \\
\hline Body Sensations Questionnaire & $3.1 \pm 1.0$ & $2.4 \pm 1.1$ & 0.008 & $2.3 \pm 1.0$ & $2.4 \pm 1.2$ & 0.739 & 56 & 52 & 0.957 \\
\hline Panic and Agoraphobia Scale (PAS) & $27.9 \pm 8.6$ & $18.6 \pm 3.4$ & 0.012 & $25.5 \pm 4.4$ & $22.4 \pm 5.3$ & 0.372 & 64 & 70 & 0.304 \\
\hline PAS - Panic Attacks & $1.4 \pm 0.5$ & $0.7 \pm 0.2$ & 0.016 & $1.4 \pm 0.5$ & $1.1 \pm 0.7$ & 0.413 & 72 & 64 & 0.149 \\
\hline PAS - Avoidance Agoraphobia & $2.4 \pm 0.7$ & $1.6 \pm 0.5$ & 0.033 & $1.7 \pm 0.8$ & $1.6 \pm 0.6$ & 0.596 & 56 & 60 & 0.965 \\
\hline PAS - Anticipated Anxiety & $2.9 \pm 0.6$ & $2.1 \pm 0.9$ & 0.028 & $2.7 \pm 1.2$ & $2.3 \pm 1.0$ & 0.235 & 52 & 48 & 0.609 \\
\hline PAS - Disability & $2.2 \pm 1.0$ & $1.6 \pm 1.0$ & 0.109 & $2.1 \pm 0.6$ & $1.9 \pm 0.7$ & 0.480 & 56 & 52 & 0.359 \\
\hline PAS - Over precaution & $2.1 \pm 0.7$ & $1.5 \pm 0.8$ & 0.117 & $2.4 \pm 0.7$ & $2.1 \pm 0.8$ & 0.465 & 60 & 68 & 0.098 \\
\hline Mobility Inventory - Accompanied & $2.4 \pm 1.1$ & $1.9 \pm 0.5$ & 0.056 & $2.1 \pm 1.1$ & $2.5 \pm 1.7$ & 0.353 & 40 & 36 & 0.235 \\
\hline Mobility Inventory - Alone & $3.5 \pm 0.9$ & $3.0 \pm 0.7$ & 0.183 & $3.2 \pm 1.6$ & $3.1 \pm 1.4$ & 0.781 & 52 & 48 & 0.869 \\
\hline Global Well-being Assessment & $60.8 \pm 12.3$ & $72.5 \pm 9.2$ & 0.015 & $66.0 \pm 20.4$ & $71.3 \pm 25.0$ & 0.139 & 68 & 60 & 0.769 \\
\hline
\end{tabular}

\# Evaluation Scales for group 1 (Cognitive Behaviour Therapy and Medication) and Evaluation Scales for group 2 (Control - with Medication and no Cognitive Behaviour Therapy). Results observed between the beginning and the end of the treatment for both groups.

\section{DISCUSSION}

These study results corroborate other research finding ${ }^{24}$, which suggest that the combination of CBT with pharmacotherapy ${ }^{19}$ produces better results than using therapy alone. The advent of effective drugs ${ }^{25}$ revolutionized the treatment of psychiatric diseases, reducing the number and length of hospitalizations and restoring quality of life for patients.

Self-evaluated quality of life evaluation improved, with reduced phobic-hypochondriac behaviour ${ }^{26}$ resulting in greater freedom in daily life. Not all mental disorders need to be treated through pharmacological approaches. Other therapeutic strategies ${ }^{27}$ are available, the physician may indicate the optimal treatment for patients, psychotherapy alone or in combination with pharmacological treatment. It is important to establish a good doctor-patient relationship and discuss all procedures and fears of the patient, such as becoming medication dependent, of being "different", sedated, etc.

Most prior research also restricted surveyed populations to patients without agoraphobia or with light agoraphobia, leaving unknown the efficiency of CBT in patients with more serious agoraphobias? ${ }^{7}$ In the population studied, all the patients showed "with agoraphobia" symptoms.

De-Melo-Neto et al. ${ }^{22}$ studied patients with respiratorysubtype PD with agoraphobia, in which specific hyperventilation exercises were used for the purpose of producing symptoms similar to panic. The objective was CR of certain negative levels of behaviour and response, and the comprehension by patients that the symptoms expressed were inoffensive and could be handled. In the present study, we also had the opportunity to observe the importance of CR in the sample studied, as this technique made an important contribution to the reduction of PD related symptoms.

During the research, it was observed that the satisfactory evolution of patients depended on several procedures, including the use of medication prescribed after the psychiatric evaluation, together with $C B T$ techniques such as $\mathrm{SIE}, \mathrm{CR}$, $R R$ and PMR exercises. At the end of the SIE, patients were able to perceive that although the sensations produced by the exercises were similar to those of panic, they did not produce the feared consequences, were inoffensive, and were caused by specific stimuli. 
This practice allows the patient to find adequate individual CR, lose the fear of being alone with his or her BS, and perceive that the physiological reactions that he or she is having are normal, that they are not originating from something serious, and that they can be handled by the patient. It was verified that patients with PD with agoraphobia lost the fear of natural BS that emerged from physiological alterations as they were able to perceive, by means of SIE, that the sensations had a triggering reason and did not arise spontaneously. Before, the patients usually made erroneous associations about their BS, interpreting tachycardia, perspiration, and breathlessness among other symptoms, as signs of imminent death or loss of control.

According to Barlow ${ }^{3}$, the proposed techniques, IE, and feared in vivo situations are widely recognised as primary, fundamental, and efficacious in the reduction of phobic anxiety reactions. According to Carvalho et al. ${ }^{2}$, the exposure of the patient to situational generators of anxiety during treatment should act as a habit-creating process, producing a reduction of anxiety in the face of stimuli that generate pathological anxiety. $\mathrm{He}^{2}$ verified the efficiency of cognitive interventions, behavioural interventions, and their combination.

Attention should be given to the improvement of important methodological aspects in studies that evaluate the efficiency of CBT, with a view toward obtaining increasingly true results, thereby indicating which directions that may contribute to the refining of the techniques used.

In making comparison between the two groups, significant differences were found in the progress of patients in the group 1 compared with the control group 2 in the scales: Sheehan Disability Scale (Total), Sheehan (Work), Sheehan (Social) and Sheehan (Family). Group 1 showed an improvement compared to group 2 in all respects. We observed in group 1 increased motivation to work and to social and family relationships after 10 sessions of CBT. We believe that these results were those that involved increased self-esteem and self-confidence due to the reduction of fears and PA.

Despite the difference found between beginning and end of treatment period, comparing the two groups was not statistically significant for the other measurements. Observing the results of group 1 individually, who received CBT intervention through the model; we found statistically significant differences between measurements performed before and after intervention in most of these parameters, indicating an improvement in clinical status.

This same improvement cannot be observed in the results of the control group, considering the same period of time. Such progress in group 1 should not be discarded, even by their clinical value.

We therefore suggest that future work on these variables can be controlled to better understand the effectiveness of CBT in the context studied. It is necessary to verify if the re- sults and differences found at the end of the treatment were actually due to CBT or to the existing variations in the profile of the group, including, physical or psychiatric comorbidity.

\section{CONCLUSION}

The techniques of SIE in the controlled laboratory setting were essential to reduce and/or remove the hyperventilation symptoms, tachycardia and changes in breathing as well as other symptoms. Patients treated with CBT had significant improvement compared to the group treated with medication. The techniques of psycho education, CR, IVE and IE, the PMR exercises and RR exercises were key to the reduction and management of symptoms in panic disorder.

Our study showed that patients with PD may lower the PA, hyperventilation and cardio vascular symptoms after the CBT sessions with SIE.

The main purpose of the study was achieved, which was to test and observe the efficacy and limitations of the proposed CBT model in the treatment of PD patients. In spite of some limitations, the results of this study showed the importance of CBT and its various techniques, in the treatment of PD with agoraphobia.

\section{ACKNOWLEDGEMENTS}

We would like to express our acknowledgements for the team of the Panic and Respiration Laboratory (LABPR/IPUB/ UFRJ, National Institute of Technological Science - Translational Medicine (INCT-TM) and the National Council for Technological and Scientific Development (CNPq) for supporting this research program.

Clinical Trial register number: NCT 00772746.

Committee of Ethics in Research (CEP - IPUB/UFRJ) Number: 07-06 Approved in 09/03/2006.

Sources of funding: National Council for Scientific and Technological Development (CNPq).

Conflict of interest: Not declared.

\section{REFERENCES}

1. American Psychiatry Association. Diagnostic and Statistical Manual of Mental disorders, 4th ed. American Psychiatry Press, Washington, DC; 1994.

2. Carvalho, MR, Nardi AE, Rangé B. Comparison between cognitive, behavioral and cognitive-behavioral approaches in the treatment of panic disorder. Rev Psiq Clín. 2008;35(2);66-73.

3. Barlow DH. Anxiety and its disorders: the nature and treatment of anxiety and panic (Edition). New York: Guilford Press; 1988.

4. Angelotti G. Terapia cognitivo-comportamental para os transtornos de ansiedade. 1. ed. São Paulo: Casa do Psicólogo; 2007.

5. King ALS, Valença AM, Nardi AE. Hiperventilação: a terapia cognitivo-comportamental e a técnica dos exercícios de indução dos sintomas no transtorno de pânico. Rev Port Pneumol. 2008;14(2):303-8. 
6. Haby MM, Donnelly M, Corry J, Vos T. Cognitive behavioral therapy for depression, panic disorder and generalized anxiety disorder: a meta regression of factors that may predict outcome. Aust N Z J Psychiatry. 2006;40(1):9-19.

7. Manfro GG, Heldt E, Cordioli AV, Otto MW. Terapia cognitivo-comportamental no transtorno de pânico. Rev Bras Psiquiatr. 2008;30(Supl II):581-7.

8. Rangé B. Transtorno de pânico e agorafobia. In: Rangé B, organizador. Psicoterapias cognitivo-comportamentais: um diálogo com a psiquiatria. Porto Alegre: Artmed; 2001. p. 145-82.

9. Stahl. Psicofarmacologia - bases neurocientíficas e aplicações práticas. 3. ed. Rio de Janeiro: Guanabara Koogan; 2010.

10. Nascimento I, De-Melo-Neto VL, Valença AM, Lopes FL, Freire RC, Cassabian LA, et al. Medicação antipânico e função pulmonar em pacientes com transtorno de pânico. Rev Psiq Clín. 2009;36(4):123-9.

11. Güntert IB, Chinalli M. Fronteiras da terapia cognitiva. 1. ed. São Paulo: Casa do Psicólogo; 2005.

12. Muotri RW, Nunes RP, Bernik MA. Exercício aeróbio como terapia de exposição a estímulos interoceptivos no tratamento do transtorno de pânico. Rev Bras Med Esporte. 2007;13(5):327-30.

13. First MB, Spitzer RL, Gibbon M, Williams JBM. Structured Clinical Interview Diagnostic (SCID) for DSM-IV Axis I Disorders - Clinician Version (SCID-CV). Washington, DC: American Psychiatric Press; 1997.

14. Beck AT, Epstein N, Brown G, Steer RA. An inventory for measuring clinical anxiety: psychometric properties. J Consult Clin Psychol. 1988:56(6):893-7.

15. Sheehan DV. The Anxiety Disease. Sheehan Disability Scale. New York, NY: Charles Scribner's Sons; 1993.
16. Marks IM, Mathews AM. Brief standard self-rating for phobic patients. Fear and Phobia Questionnaire. Behav Res Ther. 1979;17:263-7.

17. Chambless DL, Caputo GC, Bright P, Gallagher R. Assessment of "fear of fear" in agoraphobics: The Body Sensations Questionnaire and the Agoraphobic Cognitions Questionnaire. J Consult Clin Psychol. 1984.

18. Bandelow B. Panic and Agoraphobia Scale (PAS). Seattle: Hogrefe \& Huber Publishers; 1999.

19. King ALS, Valença AM, Melo-Neto VL, Nardi AE. A importância do foco da terapia cognitivo-comportamental direcionada às sensações corporais no transtorno de pânico [relato de caso]. Rev Psiq Clín. 2007;34:191-5.

20. Jacobson E. Progressive relaxation. Chicago: University of Chicago Press; 1938.

21. Briggs AC, Stretch DD, Brandon S. Subtyping of the panic disorder by symptom profile. Br J Psychiatry. 1993;163:201-9.

22. De-Melo-Neto VL, King ALS, Valença AM, Freire RC, Nardi AE. Subtipos respiratório e não respiratório no transtorno do pânico: comparações clínicas e de qualidade de vida. Rev Port Pneumol. 2009;XV(5):859-74.

23. Cordioli AV, et al. Psicofármacos: consulta rápida. Rev Psiquiatr RS. 2005;27(1):90-1.

24. Menezes GB, Fontenelle L, Mululo S, Versiani M. Treatment-resistant anxiety disorders: social phobia, generalized anxiety disorder and panic disorder. Rev Bras Psiq. 2007;29(Suppl 2):S55-60.

25. Martinez-Ortega JM, Jurado D, Martinez-Gonzalez MA, Gurpegui M. Nicotine dependence, use of illegal drugs and psychiatry morbidity. Addict Behav. 2006;31(9):1722-9.

26. Torres $A B$, Crespaldi AL. Panic disorder and hypochondriasis: a review. Rev Bras Psiquiatr. 2002;24:144-51.

27. Rangé $B$. Programa de treinamento a distância para o tratamento do transtorno de pânico e da agorafobia. Rev Psiq Clín. 2001;28(6):331-9. 